\title{
3. LA ANALOGÍA EN LA EVANGELIZACIÓN DE AMÉRICA
}

\section{INTRODUCCIÓN}

En esta parte me propongo enlazar algunos temas de la teología americana de la evangelización con la noción de analogía, que ocupa un lugar central en una hermenéutica analógica, con el fin de sacar provecho de ellos para esta propuesta y empresa filosófica y teológica.

Primero trataré el siglo XVI mexicano, que fue la época de la evangelización, y que tantos problemas encontró para la traducción de términos y conceptos cristianos para los indígenas, pues, no siempre había coincidencia. Así vemos la conveniencia de una traducción analógica, como fue la que realizó el misionero franciscano fray Juan Bautista de Viseo. Después pasaremos al dominico fray Bartolomé de Las Casas, que desarrolló una teología profética, con su defensa de los indios, en la línea del tomismo medieval y del humanismo renacentista. Por esto, trataremos tanto de su pensamiento emancipador como de las influencias humanistas que recibió, ya que algunos lo consideran solamente como escolástico, pero también tuvo una vena humanista acorde con su época. Pasaremos, finalmente, al siglo XVIII, época de la Ilustración, cuando se trae la filosofía y la ciencia modernas a nuestros lares, y se tuvo que adoptar una postura analógica, esto es, ecléctica, pues, no se podía adoptar sino lo que fuera compatible con la fe cristiana, pero, aun así, se realizó una modernización considerable. 


\section{LA EVANGELIZACIÓN: FRAY JUAN BAUTISTA DE VISEO}

Un punto importante para la teología americana fue el de la transmisión del Evangelio por los misioneros del siglo XVI. Ya en ese momento de la historia de la teología se encuentra un tema hermenéutico, que continúa hasta hoy, por lo que es de suma actualidad: los problemas de la traducción. El ejemplo que tomaremos es de gran importancia para nuestra historia cultural: fray Juan Bautista de Viseo, misionero franciscano que elaboró textos para confesores (Murillo, 2009).

Los antecedentes de este misionero son el cristianismo y España; es el contexto de origen, y el contexto nuevo es el de las Indias. El cristianismo había hecho ya una cultura, una tradición. Y fue recibido en España, la cual había realizado varias reformas. Y de allí vino al Nuevo Mundo, concretamente a México. De modo que el ideal reformista que se vivía en los franciscanos españoles del siglo XVI se quiso plasmar en estas tierras americanas. De hecho, los franciscanos milenaristas, los que creían que se llegaba a una nueva época y tenía que reformarse la cristiandad, se esforzaron por hacer realidad su proyecto en tierras mexicanas (Frost, 2002, pp. 84 y ss.).

Pasando a la Nueva España en el siglo XVI, nos topamos con sus problemas de evangelización. El más importante era el de la traducción. ¿Cómo trasladar a una cultura tan diferente el mensaje evangélico? No siempre se tenían los moldes lingüísticos o antropológicos para hacerlo. Por eso, se nos presenta el advenimiento de las primeras generaciones de franciscanos, con su ímpetu tan grande en lo que Robert Ricard llamó la conquista espiritual, muy distinta de la material, que efectuó la soldadesca a base de armas. Allí aparecen los trabajos de fray Juan Bautista de Viseo. Sabemos de los textos 
para confesores que escribieron él, Molina y Focher, pues, una de las cosas más difíciles para enseñar a los indios fue la noción de pecado. Ellos no la tenían en su religión, y muchas veces no comprendían lo que se les decía de parte del cristianismo. Por ello, se hicieron confesonarios, no como el de Bartolomé de Las Casas, que era para españoles y donde el pecado principal era el de esclavizar a los indios, sino confesonarios para los indios, donde se trataba de inculcarles conciencia de pecado, por ejemplo de la idolatría, del robo, de la falta sexual, etcétera, cosas que, a veces, no tenían en su pasado. Recuérdense los famosos catecismos pictóricos, donde se trataba de enseñarles con figuras, pero, a veces, estaban llenos de equívocos, o de cosas mal adaptadas y forzadas, como la idea del diablo, del infierno, etcétera. En ello se usó la analogía; por ejemplo, se aprovechó que los indios tenían una especie de infierno, un mundo de los muertos, con su cielo y con su averno, y se asoció al diablo con alguna de sus divinidades paganas.

Llegando a la traducción, se nos presentan dos tesis extremas, tomadas de Steiner: la universalista y la monadista. La universalista sostiene que la traducción es posible porque hay universales genéticos, sociales y culturales, de los cuales se derivan los lingüísticos (Murillo, 2009, p. 54); la monadista sostiene que la traducción es imposible, porque la correspondencia entre las palabras y los significados es muy discordante. Pero cabe colocarse entre una y otra, sosteniendo que la traducción es posible porque es posible conmensurar las distintas culturas y hacer que se refieran más o menos al mundo con cierta unidad. Esto es evitar dos posturas extremas, una univocista y otra equivocista, y buscar una postura intermedia, que yo denomino analógica. Está en la línea de lo que he tratado de sostener con lo que llamo bermenéutica analógica. 
Por eso, de manera coherente, hay que abordar los límites de la traducción. Es decir, toda traducción es limitada: no puede ser unívoca con el original, porque siempre hay cierta pérdida o irreductibilidad, pero tampoco puede ser, por supuesto, equívoca, porque siempre tiene que haber cierta conmensuración entre las culturas. La experiencia nos dice que, mal que bien, podemos comunicarnos entre las culturas. Aquí hay tanto problemas metodológicos, de cómo hacer la traducción, como problemas epistemológicos, de hasta dónde se puede traducir, o incluso si es posible traducir, o si se encuentra lo intraducible.

Avanzando a la traducción, en la Nueva España, de la religión cristiana para la cultura indígena, tenemos que tomar en cuenta la enorme distancia entre esta y la cultura europea, cristiana. En verdad, la una y otra eran muy diferentes. Surgía una gran necesidad de traducir, de ver la evangelización como traducción, porque el contenido del mensaje evangélico tenía cosas muy extrañas para los indígenas, con el riesgo de la intraducibilidad. Podemos imaginar todo lo que se hizo para la traducción del mensaje evangélico al náhuatl, con la pérdida y el empobrecimiento que ello supone. Pero podemos colocarnos en una postura intermedia y mediadora, a saber, sosteniendo que se alcanzó lo suficiente para evangelizar, a pesar de las deficiencias tan grandes que en ello se dieron. Es, como digo, una postura hermenéutico-analógica, que trata de evitar la ilusión de una traducción unívoca, en la que todo se entendió, y también evitar la decepción de una traducción equívoca, en la que no se logró trasladar nada de una cultura a otra. Hubo pérdida, empobrecimiento, pero se logró una cierta conmensuración en la traducción y en la comunicación del mensaje.

Un ejemplo muy claro (por lo difícil y complicado) es el de los problemas de la traducción en los manuales de confesores. Allí 
cobra sentido la intención de las obras de fray Juan Bautista de Viseo, pues, fueron elaboradas con el fin de ayudar a la confesión de los naturales. Pero había un enfrentamiento de cosmovisiones, lo cual dificultaba la comunicación grandemente; por eso, hubo que hacer antes una labor antropológica, para poder acercar las dos culturas. Ello provocó el que se tuvieran que hacer esos tratados, en los que se ensayaba la traducción del mensaje evangélico a la cultura indígena, con todo lo de inconmensurable que eso comportaba. Podemos captar eso tanto en la conversión misma, pues, muchas cosas no quedaban claras a los indios conversos, como en la confesión, pues, no entendían el significado cristiano de muchos pecados, y había que dárselo a entender. El ejemplo más connotado es el de la Santísima Trinidad. ¿Cómo hacerles entender que era un solo Dios pero en tres personas distintas? De inmediato se piensa que estaban entendiendo lo de tres personas como tres dioses diferentes, según el pasado politeísta que habían tenido. Fueron, en verdad, grandes los problemas que tuvo que afrontar la predicación.

Todo esto nos conduce a la comprensión de que se tuvo que construir un lenguaje y un mundo comunes. Si no hay un lenguaje que se comparta, no se puede tener un mundo en común. Por eso, tal fue la gran empresa que se realizó en la evangelización. Tratar de unificar el lenguaje, para unificar el mundo, para dar una nueva cosmovisión a los indígenas que fuera coincidente con la de los españoles. Era algo dificilísimo. Y, sin embargo, algo se logró. Aunque siempre recuerda uno lo que contaba fray Diego Durán, de que, regañando una vez a un indio porque estaba actuando según los moldes de su anterior religión, el indio le dijo: "No te fijes tanto, padre, que estamos nepantla" (Frost, 2004, p. 5). Es decir, estaban en medio. Esto lo entendió bien Durán, y explicó que estaban neutros, entre una religión y la otra, pero añadió que había que impulsarlos con más fuerza para entrar en la nueva religión. 
Todo esto pertenece a nuestra historia cultural. Y, de manera muy especial, nos da ocasión para volver a estudiar los problemas de la traducción, pero en concreto, con ejemplos bien delimitados, lo cual nos muestra la importancia de la traducción, de la hermenéutica, que es la que tiene que ver con ese intercambio de significados. Fue lo que hizo fray Juan Bautista de Viseo, en los albores de la cristianización de América y, por lo tanto, de la historia de la teología cristiana latinoamericana. Viseo, al igual que fray Bernardino de Sahagún (Hernández de León Portilla, 2009, pp. 87 y ss.), fue un verdadero hermeneuta analógico. Por eso, también nos hace captar la pertinencia de una hermenéutica analógica para la traducción, específicamente para la evangelización, que tiene que darse en el seno de un diálogo intercultural.

Esa hermenéutica analógica, implementada por los misioneros, que fueron también teólogos, fue la que les permitió comprender lo que alcanzaron de la otra cultura, tan diferente. Y fue asimismo lo que los capacitó para poderse comunicar con los indígenas, cosa sumamente difícil. La muestra está en esos dilemas de la traducción, lo que tuvieron que esforzarse para poder transmitir el mensaje revelado. Lo que llegaron a alcanzar de adecuación les fue dado por la analogía que supieron utilizar en ese intento.

Asimismo, esto forma parte de la historia de la teología en América Latina. Fueron los inicios, los orígenes, tan difíciles y complejos, cuando se trató de entregar el mensaje cristiano a los indígenas de estas tierras. Tuvo que usarse una traducción no unívoca, pero tampoco equívoca, para darles a conocer el Evangelio. Por eso, podemos decir que en ello se utilizó y aplicó una hermenéutica analógica, que aprovechó los moldes de la analogía, del conocimiento analógico, para transmitir el mensaje evangélico. Y es lo que todavía, en nuestros ambientes de multiculturalismo, nos toca desarrollar. 


\section{LA TEOLOGÍA PROFÉTICA: FRAY BARTOLOMÉ DE LAS CASAS}

En la línea de la evangelización y los misioneros, y más del lado de la tradición dominicana, encontramos a Bartolomé de Las Casas. Fue célebre por su defensa de los indios americanos, labor que realizó desde su bagaje doctrinal. Veremos que en ello utilizó mucho la noción de analogía, teniendo una verdadera hermenéutica analógica, aplicada en su desempeño pastoral.

Mario Ruiz Sotelo (2010, pp. 75 y ss.) ha sabido presentarnos a un Bartolomé de Las Casas como hermeneuta analógico, es decir que usó la noción de la analogía para comprender al otro. Sobre todo, su trabajo fue realizado con una hermenéutica diferente, muy adecuada para considerar la labor y el pensamiento lascasianos. Es una hermenéutica planteada desde nuestra situación, para tratar de comprender a Las Casas desde nuestra situación propia, como un prototipo o paradigma de hacer filosofía y teología desde América Latina.

Comencemos con la construcción intelectual de Las Casas. Era un doctrinero o catequista que había recibido indios en repartimiento o encomienda, es decir, era un encomendero. Por eso, puede llamársele el encomendero arrepentido, o, como le dice Agustín Yáñez, es el conquistador conquistado. Fue conquistado para la causa de los indios, por haber visto su realidad y, además, por la predicación de otro dominico: Antón de Montesinos, que se encaró a los conquistadores en la isla de La Española y les dijo en su célebre sermón: “¿Que estos no son hombres? ¿Que no tienen ánimas racionales?’”. El grito de Montesinos en su homilía llegó hasta Bartolomé, y lo hizo cambiar. Fue como dejó la encomienda, o repartimiento, se ordenó sacerdote y fue dominico. Dentro de la Orden dominicana 
continuó su formación, en la línea del tomismo de esta corporación, y empezó a escribir sus voluminosas obras.

Fue el tomar conciencia de la semejanza de los otros. El reconocer al otro como semejante, como análogo, y no dejarlo como extraño, como alguien que es casi un objeto. A esto concurrió para reforzar la bula Sublimis Deus, emitida por el papa Paulo III, en la que declaraba racionales a los indios y condenaba la esclavitud. Fue conseguida, sobre todo, por Bernardino de Minaya, dominico cercano a Montesinos, a Las Casas y a los acontecimientos mismos, que fue capaz de acudir al papa, con la ayuda del entonces general de los dominicos, Tomás de Vio, que sería después el cardenal Cayetano o de Gaeta, el gran sistematizador de la doctrina tomista de la analogía.

Así se lograron las Leyes de Indias, en buena medida por la labor del propio Bartolomé de Las Casas, el cual fue, de paso, nombrado defensor de los indios y también obispo de Chiapas. Hay que recordar cómo Las Casas se mantuvo firme en la polémica de Valladolid, de 1550, frente a Juan Ginés de Sepúlveda. Allí estuvo presente Domingo de Soto, gran filósofo y teólogo, sobre todo, eminente lógico, quien, precisamente, tomó nota de las argumentaciones que se dieron de un lado y del otro, y señalaba los aciertos y las fallas de uno y de otro. Llega a indicar algunos argumentos malos que esgrimió Las Casas, y cómo podía haberlos mejorado. Pero hizo ver cómo el obispo ganaba la polémica.

En el paso de Las Casas por la Corte española, encontramos un elemento de humanismo en él, pues, en ella conoció a muchos personajes de origen flamenco, que venían con Carlos $\mathrm{V}$, y que tenían contacto con el círculo de Erasmo de Róterdam. De allí le vino una influencia humanista, al igual que de Tomás Moro, quien, con su Utopía, animaba a muchos a tratar de aplicarla en las Indias, como 
pasó también con don Vasco de Quiroga. Ambos obispos compartieron esa admiración por la utopía de Moro.

Aquí se nos presenta la postura de Las Casas frente al descubrimiento de América. Para él sí fue una invención verdadera, pues, descubrió al indio en su ser propio; por eso, me parece correcto decir que Las Casas respetó la autonomía ontológica de América. Es decir, supo reconocer y respetar a los indios en su propia onticidad, en su ser peculiar y diferente del suyo. Incluso llega a reconocer un humanismo indígena, como lo asienta en la Apologética historia sumaria, humanismo diferente del europeo, que Sepúlveda no fue capaz de reconocer.

Algo muy interesante es lo que nos resulta de una reflexión sobre la hermenéutica lascasiana. Bartolomé supo trascender la idea aristotélica de que eran bárbaros y, por lo mismo, esclavos o siervos por naturaleza. Inclusive hay que notar aquí que fue capaz de usar el comentario del ya mencionado Cayetano a la Suma teológica de santo Tomás, donde distingue diversos tipos de bárbaros, y hacer ver que los indios no caben en ninguno de ellos. También usa su distinción de las clases de infieles, y señala que, en todo caso, pertenecen a los que nunca han atacado a los cristianos y que, por ello, no se les puede privar de su dominio. Además, recalca que la infidelidad no quita el derecho al dominio, esto es, a tener posesiones.

Ruiz Sotelo (2010, pp. 99-110) encuentra aquí una hermenéutica analógica usada por Las Casas. Este hizo uso de la noción de analogía, para equiparar la cultura indígena con la europea y mostrar que, proporcionalmente, es decir, guardadas las proporciones, eran tan cultos los unos como los otros, cada uno con un humanismo distinto. Salvando las diferencias innegables, estaban en paridad de civilización.

Hay aquí un rasgo de modernidad que se puede señalar en Las Casas, el cual lo llevó a reconocer, después de los indios, a los negros. 
Él había pedido que se trajeran esclavos negros de África porque eran más resistentes que los indios, y porque los indios estaban casi a punto de desaparecer, acabados por el genocidio y los trabajos forzados. Pero luego se dio cuenta de su error, y lo deploró mucho, y se convirtió en defensor tanto de los negros como de los indios, y escribió lo que podría llamarse la defensa de los negros, en su Historia de las Indias, que Isacio Pérez Fernández extractó y recopiló con el nombre de Brevísima relación de la destrucción de África (1989). Allí cuenta Las Casas cómo los franceses y los portugueses se dedicaron al comercio de esclavos africanos, aprovechando que ya había venta de ellos en las costas y, a veces, haciendo ellos mismos sus cacerías o pequeñas guerras de las que sacaban a los siervos.

Igualmente, destacada fue la lucha de Las Casas por la libertad religiosa. De hecho, fue el que más claramente señaló que no se puede obligar a nadie a la conversión, ni siquiera a escuchar la predicación. Dejaba de lado a Duns Escoto, que sí permitía la conversión forzada, lo cual aceptaron algunos franciscanos, y se atenía a santo Tomás, quien no aceptaba la conversión forzada, pues, si no hay plena conciencia y voluntad, es inválida. Por eso, en su libro De unico vocationis modo, dice que la única manera válida de llamar a las gentes a la conversión es sin violencia y solo mediante la persuasión.

Así, lo político en Las Casas surge de su afán de defender el dominio y la propiedad de los indios, a la manera como lo hará Alonso de la Vera Cruz, y eso fue prestar pensamiento filosófico al fenómeno de las Indias, fue dar filosofía a los acontecimientos que lo necesitaban, que lo solicitaban con urgencia. En ese sentido, Las Casas es, verdaderamente, un filósofo latinoamericano, y de los grandes como lo hace ver Ruiz Sotelo. Solamente, la libre voluntad del gentil, del indígena, puede legitimar la evangelización. También tienen derecho a su propio gobierno, y solo se justificaría la intervención española si los indios la aceptaran libremente, lo cual nunca 
fue el caso. Estaba aplicando Las Casas el derecho natural a la situación de los indios, y señalaba sus derechos naturales, antecedentes de nuestros derechos humanos.

En esta constitución de la autonomía de los indígenas, Las Casas supo señalar la soberanía de los pueblos, que no pueden tocar las falsas soberanías universales del papa y el emperador, que solo la creían sus aduladores. Con ello, hace crítica del absolutismo y de la razón imperial. Por eso, Bartolomé está más allá de la modernidad, puesto que la critica ya en sus inicios.

Con todo esto, Mario Ruiz Sotelo ha sabido resaltar las notas más características e importantes de la labor y el pensamiento de Las Casas. Es algo que va a quedar como reflexión sobre este complejo personaje. Sobre todo, posee, creo yo, el mérito de enfocar el estudio de Las Casas desde la hermenéutica. Ha sabido sacar lo que él mismo llama la hermenéutica lascasiana, la cual es una hermenéutica basada en la analogía, en el reconocimiento del otro como semejante, como ser humano inequívoco, como prójimo igual a nosotros, a pesar de su diferencia, de su otredad. Ha apuntado hacia el carácter analógico de la hermenéutica de Bartolomé.

En efecto, Las Casas emplea una hermenéutica analógica al hablar de la otra cultura, sobre todo, en su Apologética historia sumaria (Beuchot, 2009b, pp. 13-24), en la que hace la apología o defensa de los indios comparando su cultura con la europea, señalando la de los griegos y romanos, que tanto admiraban los humanistas de su tiempo. Muchas de las cosas (idolatría, sacrificios, etcétera), de las que los humanistas acusaban a los indios, habían sido cometidas por griegos, romanos y otras culturas antiguas. Compara sus dioses con los dioses paganos de la gentilidad clásica, y aun con algunos santos cristianos, con lo cual acierta a comprender de alguna manera su significado. Así, también trata de entender los sacrificios humanos, por 
los que los indígenas trataban de entregar lo mejor de ellos mismos a la divinidad, tal como la concebían. Esa misma consideración analógica ayudó a Bartolomé a valorar el humanismo indígena, diferente del europeo, pero tan valioso como este.

Es, sobre todo, allí donde se ve la presencia del humanismo en Las Casas. Pues, no solo tuvo una actitud humanista frente a los indígenas, sino que supo reconocer el humanismo indio. No se quedó, como Sepúlveda, en el humanismo europeo, con una mentalidad eurocentrista, sino que dio un paso más, al captar rasgos humanistas en las culturas americanas, por analogía con el humanismo de la cultura europea. El humanismo y la escolástica, corrientes que se reunían en Salamanca, dieron en Bartolomé sus frutos, y cada una de ellas aportó algo a la lucha que él libró a favor de los naturales.

De esta manera, con esa comprensión, Las Casas tuvo una base muy buena para realizar su misión evangelizadora con los indios. Captó de manera muy notable su humanidad, la cual defendió contra los que los consideraban seres inferiores y se valían de ello para esclavizarlos. Y no solamente los protegió contra los esclavistas, sino que también llegó a captar el humanismo indígena, los valores de esa otra cultura, tan diferente, por obra de la analogía. Asimismo, eso le valió el poder buscar leyes adecuadas que los protegieran y les dieran un ámbito de justicia.

Por eso, podemos indicar en Bartolomé de Las Casas una hermenéutica analógica aprovechada para hacer teología. Para construir esa teología kerigmática o de la misión, que sirvió de apoyo y de modelo a muchos misioneros y teólogos que vinieron después. Misioneros teólogos, o teólogos misioneros, que hicieron tan gran teología profética en los albores de nuestra Iglesia latinoamericana. Una hermenéutica analógica estuvo presente en ella, no solamente en Las Casas, sino también en otros más, pero ahora nos hemos 
detenido en él, que es un paradigma de la teología latinoamericana, y de la teología universal, pues, reflexionó teológicamente sobre los problemas más candentes y perentorios de su momento, es decir, sobre la realidad misma, y supo comprender a la cultura otra, la diferente, para conducirla a la aceptación del Evangelio. Es, por eso mismo, uno de los paradigmas de nuestra tradición teológica.

\section{CONCLUSIÓN}

En los dos ejemplos que hemos escogido, encontramos cómo en la historia de la teología americana se han dado posturas que se acercan a la analogía, es decir, que tratan de evitar los extremos univocista y equivocista. Han sido momentos fugaces y a veces solo aproximativos, pero son suficientes para hacernos ver que en la historia de nuestro pensamiento teológico ha habido intentos de llegar a una hermenéutica analógica.

Se dio en la época de la evangelización, pues, misioneros que entendieron mínimamente a la otra cultura, como Sahagún y fray Juan Bautista de Viseo, lo hicieron gracias a un procedimiento por analogía, por un razonamiento por analogía. Esto se ve, sobre todo, en la traducción, como se tuvo que hacer para dar a conocer el Evangelio a los indígenas. También se percibe en Bartolomé de Las Casas, el cual aplicó una hermenéutica analógica para comprender la cultura indígena, tan diferente de la suya, y para producir una teología acorde con las necesidades de su momento. Con ello, podemos decir que, en la teología americana, hubo acercamientos, muy notables, a la analogicidad, a una hermenéutica analógica, como lo vimos en el ejemplo que hemos seleccionado. Ella es la que nos podrá llevar a actualizar y a hacer proporcionada nuestra teología a los requerimientos de nuestro tiempo. 
